\title{
Spectrum survey: Attending scientific conferences and meetings
}

\author{
BY ANGIE VOYLES ASKHAM
}

16 SEPTEMBER 2021

Calling all autism researchers: How are you approaching upcoming conferences and meetings, such as the annual Society for Neuroscience meeting this November, which will be held both virtually and in person? Are you eager to get back to in-person gatherings? Are face-to-face encounters critical to advancing your work? Or are you hesitant to travel? Enjoying the convenience of conferencing from home? Waiting to decide?

Spectrum is working on a story about scientists' conference plans through the end of this year. The coronavirus pandemic has dramatically altered how scientists share their work - with some effects that may reverberate for years to come. Please help us report this story by taking a short survey about your plans and decision-making process.

Cite this article: https://doi.org/10.53053/OXCT4853 